\title{
Reflexões acerca da organização curricular e das práticas pedagógicas na EJA
}

\section{Reflexions about curricular organisation and pedagogical practices in adult education}

\author{
Inês Barbosa de Oliveira*
}

\begin{abstract}
RESUMO
Esse texto aborda alguns pontos da reflexão curricular contemporânea, no que se refere ao estudo de novas formas de organização curricular destinadas à educação de jovens e adultos. Em seu início, traz uma breve abordagem histórica a respeito da educação de jovens e adultos no Brasil, que tem por objetivo situar o leitor no debate. Depois, partindo de relatos de situações reais vivenciadas pela autora ou por pessoas próximas, são discutidos alguns dos principais problemas que percebo nas práticas curriculares desenvolvidas na educação de jovens e adultos, como a infantilização dos educandos ou inadequação de conteúdos e modos de abordá-los, bem como de linguagem. A partir disso, uma reflexão mais teórica a respeito de como entendo os processos de tessitura de conhecimentos é desenvolvida, pretendendo contribuir para a reflexão em torno das possibilidades de superação destes problemas. Finalmente, discuto algumas concepções de currículo e seus fundamentos para chegar à proposição de um debate sobre as possibilidades de novos desenhos curriculares que possam ser mais adequados aos nossos alunos da EJA do que as propostas tradicionais.

Palavras-chave: educação de jovens e adultos; currículos praticados; organização curricular na EJA.
\end{abstract}

* Professora adjunta da Faculdade de Educação e do Programa de Pós-Graduação em Educação da UERJ. Membro do GT Currículo da ANPEd. E-mail para contato: inesbo@terra.com.br. 


\begin{abstract}
This text approaches some points about the contemporary curricular reflection, referring to the study of new forms of curricular organization bound for the youth and adults education. In its beginning, the text brings a brief approach of the history of the youth and adults education in Brasil, aiming to place the reader in the debate. Then, using the relates of real situations lived by the author or by close people, I discuss some of the main problems that can be perceived in the curricular practices developed in the youth and adult education, as the childish treatment of the students or the inadequate contents or way of treating them and the speech used as well. From this, a theoretical reflection about how I understand the process of weaving the knowledge is developed, where I intent to contribute to the reflection around the possibilities of overcoming these problems. Finally, I discuss some of the conceptions of curriculum e yours fundaments to reach the proposition of a debate about the possibilities of new curricular drawings that may be more fitted to the students than the traditional proposes.

Key-words: adult education; practiced curriculum; curricular organization for adult education.
\end{abstract}

\title{
Introdução
}

O objetivo deste texto é contribuir, através de uma reflexão fundamentada em estudos do campo do currículo, com o debate contemporâneo a respeito da EJA e das especificidades que as atuais políticas, social e econômica, lhe atribuem. Não se pretende, em nenhum momento, trazer receitas ou soluções mágicas para os tantos problemas que se apresentam àqueles que fazem o dia-a-dia dos tantos espaços/tempos em que a EJA acontece. Assim, o texto aborda alguns pontos da reflexão curricular, que podem contribuir com o debate, sem pretender esgotá-lo. Primeiramente, abordo um pouco do histórico da EJA, por considerá-lo fundamental para nos situarmos no debate. Depois, discuto, a partir de situações reais, alguns dos principais problemas que percebo nas práticas curriculares reais no campo para trazer uma reflexão mais teórica a respeito de como entendo os processos de tessitura de conhecimentos. Finalmente, discuto algumas concepções de currículo e seus fundamentos para chegar à proposição de um debate sobre as possibilidades de novos desenhos curriculares 
que possam ser mais adequados aos nossos alunos da EJA do que as propostas tradicionais.

\section{Um pouco de história}

Retomo, aqui, discussão de texto anterior (OLIVEIRA e PAIVA, 2004) para dizer que a educação de jovens e adultos tem sido, no Brasil, um tema polêmico e controvertido desde os primeiros momentos em que começou a ser pensada em suas especificidades com relação ao ensino regular. Sem pretender apresentar um estudo a respeito do histórico dessa problemática, acho importante recuperar alguns dados. Localizada inicialmente numa perspectiva prioritariamente voltada para a alfabetização dos segmentos da população a quem o acesso à escolarização regular foi prejudicado, a educação de jovens e adultos encaminhava-se para uma visão compensatória na qual o objetivo de alfabetizar não se fazia acompanhar de um reconhecimento da especificidade dos alfabetizandos.

Quando Paulo Freire, em Pernambuco, e Moacir de Góes, no Rio Grande do Norte, começaram a desenvolver seus trabalhos de alfabetização, fundamentados em métodos e objetivos que buscavam adequar o trabalho à especificidade dos alunos, começou a emergir a consciência de que alfabetizar adultos requeria o desenvolvimento de um trabalho diferente daquele destinado às crianças nas escolas regulares. As necessidades e possibilidades daqueles educandos exigiam o desenvolvimento de propostas adequadas a elas. Em virtude do caráter explicitamente político do trabalho de ambos, que reconheciam a educação como ato político por excelência, depois de um primeiro momento em que o governo de João Goulart encampou e propôs um Programa Nacional de Alfabetização fundamentado no então chamado "Método Paulo Freire", a partir do golpe militar de 1964 procurou-se enterrar a proposta e sua lógica.

Os sucessivos programas de alfabetização de adultos propostos pelos governos militares, e mesmo pelos que lhes sucederam a partir de 1985, além das dificuldades que apresentaram na adequação das propostas curriculares e metodológicas à faixa etária e ao perfil socioeconômico-cultural dos educandos, tenderam quase sempre à apresentação de propostas únicas para todo o país, desconsiderando as nossas múltiplas especificidades regionais. 
Uma última questão histórica relevante para pensarmos o currículo na educação de jovens e adultos diz respeito ao entendimento a respeito de quem são as pessoas a que ela se destina. Na perspectiva dominante, educação de jovens e adultos é aquela que se volta para atividades educativas compensatórias, ou seja, para a escolarização de pessoas que não tiveram a oportunidade de acesso à escolarização regular prevista na legislação. Desaparecem, portanto, do campo de reflexão da EJA, os jovens e adultos que freqüentam a escola regular, seja no ensino médio seja na universidade. Atualmente, muitos são os educadores que buscam ampliar este conceito, incorporando ao trabalho e à reflexão sobre o tema os jovens e adultos que, estando no sistema de ensino regular, são submetidos a propostas e práticas inadequadas tanto aos seus perfis socioeconômico-culturais quanto às suas possibilidades e necessidades reais. Isto porque a tendência predominante das propostas curriculares é a da fragmentação do conhecimento, e a da organização do currículo numa perspectiva cientificista, excessivamente tecnicista e disciplinarista, que dificulta o estabelecimento de diálogos entre as experiências vividas, os saberes anteriormente tecidos pelos educandos e os conteúdos escolares.

Diante desse quadro, a reflexão que proponho desenvolver aqui se dá em dois tempos: um primeiro, no qual discutirei os problemas que decorrem da inadequação das propostas aos adultos que não tiveram oportunidade de se escolarizar no "tempo devido" e, posteriormente, aqueles que se relacionam aos processos pedagógicos mais amplos que envolvem jovens e adultos, mesmo os do ensino regular. Considerando que ambos estão relacionados à própria concepção dominante a respeito dos modos como os processos de tecitura de conhecimentos se desenvolvem, fundamentada na imagem da "árvore do conhecimento", antes de abordá-los, apresento uma breve discussão a respeito da noção de tecitura do conhecimento em rede, que busca superar os problemas inscritos na concepção dominante.

\section{A tessitura do conhecimento em rede e as propostas curriculares}

Segundo esta noção, o conhecimento se tece em redes que se tecem a partir de todas as experiências que vivemos, de todos os modos como nos inserimos no mundo à nossa volta, não tendo, portanto, nenhuma 
previsibilidade nem obrigatoriedade de caminho, bem como não podendo ser controlada pelos processos formais de ensino/aprendizagem.

A idéia da tecitura do conhecimento em rede busca superar não só o paradigma da árvore do conhecimento, como também a própria forma como são entendidos os processos individuais e coletivos de aprendizagem cumulativos e adquiridos - segundo o paradigma dominante. A idéia da construção do conhecimento usando a imagem da árvore pressupõe linearidade, sucessão e seqüenciamento obrigatório, do mais simples ao mais complexo, dos saberes aos quais se deve ter acesso. Além disso, pressupõe a ação externa como elemento fundador da "construção" de conhecimentos. A idéia da tecitura do conhecimento em rede pressupõe, ao contrário, que as informações às quais são submetidos os sujeitos sociais só passam a constituir conhecimento quando se enredam a outros fios já presentes nas redes de saberes de cada um, ganhando, nesse processo, um sentido próprio, não necessariamente aquele que o transmissor da informação pressupõe. Isso significa que dizer algo a alguém não provoca aprendizagem nem conhecimento, a menos que aquilo que foi dito possa entrar em conexão com os interesses, crenças, valores ou saberes daquele que escuta. Ou seja, os processos de aprendizagem vividos, sejam eles formais ou cotidianos, envolvem a possibilidade de atribuição de significado, por parte daqueles que aprendem, às informações recebidas do exterior - da escola, da televisão, dos amigos, da família etc. (Cf. OLIVEIRA, 2003)

Considerando a singularidade das conexões que cada um estabelece, em função de suas experiências e saberes anteriores e, também, a multiplicidade de conexões possíveis, não faz sentido pressupor um trajeto único e obrigatório para todos os sujeitos em seus processos de aprendizagem. Cada um tem uma forma própria e singular de tecer conhecimentos através dos modos como atribui sentido às informações recebidas, estabelecendo conexões entre os fios e tecituras anteriores e os novos. Esse entendimento coloca novas exigências àqueles que pretendem formular propostas curriculares que possam dialogar com os saberes, valores, crenças e experiências dos educandos, considerando-os como fios presentes nas redes dos grupos sociais, das escolas/classes, dos professores e dos alunos e, portanto, relevantes para a ação pedagógica. O formalismo e a fragmentação dos saberes que vêm caracterizando a grande maioria das propostas curriculares que conhecemos poderiam, assim, ser superados.

Uma última questão a esse respeito precisa ser abordada, e é a que se refere aos processos de tecitura dessas redes. Todos os aspectos da realidade vivenciada, dos hábitos familiares aos programas de televisão assisti- 
dos, passando por experiências sociais mais amplas, bem como pela vida afetiva e familiar, contribuem para a tecitura das redes de subjetividades (SANTOS, 2000) que cada um é e das redes de saberes que as constituem. Em todos esses espaços, estamos inseridos e tecemos nossas redes de subjetividades. Portanto, restringir o entendimento da ação pedagógica aos conteúdos formais de ensino constitui uma mutilação não só dos saberes que se fazem presentes nas escolas/classes, mas dos próprios sujeitos, à medida que fragmenta suas existências em pequenas "unidades analíticas" operacionais incompatíveis com a complexidade humana.

Alguns dos problemas que enfrentamos nas escolas e classes decorrem exatamente dessa organização curricular que separa a pessoa que vive e aprende no mundo daquela que deve aprender e apreender os conteúdos escolares. No caso da EJA, um outro agravante se interpõe e se relaciona com o fato de que a idade e vivências social e cultural dos educandos são ignoradas, mantendo-se nestas propostas a lógica infantil dos currículos destinados às crianças que freqüentam a escola regular.

\section{A infantilização como regra: experiências vividas e trabalhos escolares}

Esse é, possivelmente, um dos principais problemas que se apresentam ao trabalho na EJA. Não importando a idade dos alunos, a organização dos conteúdos a serem trabalhados e os modos privilegiados de abordagem dos mesmos seguem as propostas desenvolvidas para as crianças do ensino regular. Os problemas com a linguagem utilizada pelo professorado e com a infantilização de pessoas que, se não puderam ir à escola, tiveram e têm uma vida rica em aprendizagens que mereceriam maior atenção, são muitos.

Convidada a ministrar um curso de formação de professores atuando na EJA, vivenciei duas situações que evidenciam este problema da inadequação das propostas curriculares ao público da EJA. Em primeiro lugar, ao propor aos professores cursistas que estes falassem do seu trabalho, dos problemas e dificuldades nele enfrentados, deparei-me com depoimentos semelhantes aos que ouvia no tempo em que atuava no $1^{\circ} \mathrm{seg}$ mento do ensino fundamental, com crianças de 6 a 10 anos, frases que me 
fornecem indícios de que a mudança de faixa etária e de histórico de vida não trazem consigo uma mudança na proposta de trabalho: "a aluna não consegue entender a folhinha"; "eu mando o dever de casa e eles não trazem". Considerando que o público dessas classes é de pessoas entre 20 e 75 anos de idade, fica evidente que o termo "folhinha" usado pela professora deve causar estranhamento ao grupo e, muito possivelmente, realimentar a baixa auto-estima que caracteriza muitos desses grupos e que decorre do processo de "culpabilização da vítima" presente em nossa sociedade meritocrática e individualista. Ou seja, o uso do diminutivo relembra permanentemente ao aluno da EJA que aquele lugar que ele ocupa naquela classe configura uma distorção. Além disso, se a folha do aluno é do mesmo tamanho que a do professor, por que o diminutivo? (Tenho questionado esse linguajar infantilizante mesmo na escola regular, por entender que ele desqualifica o aluno ao tratá-lo de maneira artificialmente infantil através do excesso de diminutivos.)

Quanto ao dever de casa, acredito que o nobre objetivo da atividade é o de criar hábitos e disciplina de estudo em crianças que vão prosseguir na escola e que estão em processo geral de formação, além da facilitação da "fixação" do conteúdo trabalhado. Porém, me pergunto qual é a possibilidade real que tem um adulto, sem hábitos de lidar com atividades organizadas do modo como o são as escolares e que, na maior parte das vezes, trabalha o dia inteiro, de fazer sozinho o dever de casa. Mais ainda, pergunto-me qual é a função do dever de casa nessas circunstâncias, considerando o fato de que a criação da disciplina no estudo, importante como formação geral das crianças, não se aplica a este público e que a própria idéia de fixação de conteúdos pressupõe uma concepção de aprendizagem inadequada aos objetivos da escolarização de jovens e adultos? Sem pretender julgar professores e professoras que buscam desenvolver da melhor maneira possível o seu trabalho docente, acredito ser fundamental compreendermos o quanto esta lógica prejudica os alunos da EJA, na medida em que reforça, mais do que resolve, os problemas que os obrigaram a deixar a escola, na medida em que a torna incompatível com as necessidades e interesses das suas vidas cotidianas.

A outra situação é ainda mais significativa. Angustiada com uma aluna de $2^{\mathrm{a}}$ série e de 75 anos que não conseguia aprender matemática e preocupada com a possibilidade de ela desistir da escola, uma professora cursista me pediu ajuda para solucionar o problema. Dizia-me ela: "Professora, o que eu faço com a Dona Josefa (o nome é fictício)? Ela não consegue fazer as continhas de jeito nenhum! Ela não sabe fazer e não consegue apren- 
der". Solidária com a professora, nitidamente comprometida com o seu trabalho, vi que ela precisava de socorro. Refletindo sobre o problema, perguntei-lhe sobre a vida de Dona Josefa, uma senhora que morava na periferia do município, mãe de muitos filhos e avó de muitos netos, sempre responsável pela criação de muitos deles. Como se explica que uma pessoa, que provavelmente passou a vida contando dinheiro para alimentar, vestir e dar casa a tantos filhos e netos, não consiga aprender a fazer contas. Parece-me impossível, mesmo sabendo dos problemas enfrentados nos supermercados por pessoas que chegam ao caixa com uma cesta de produtos e os colocam diante do caixa pela ordem de prioridade, considerando encerrada a sua compra quando o subtotal atinge a quantidade de dinheiro de que dispõem. Ou seja, se é verdade que muitos são aqueles que compram coisas e vivem sem fazer as contas, é também fato que, se o ensino da aritmética estivesse vinculado à possibilidade de evitar esse constrangimento, talvez o interesse pela aprendizagem da matéria se ampliasse. Ou seja, se, notadamente de EJA, os conteúdos aparentemente abstratos fossem trabalhados em relação com sua utilidade concreta, a escola poderia ter, na adesão dos alunos à necessidade de aprendizagem deles, um contributo fundamental para a facilitação dos processos pedagógicos.

Voltando ao problema da professora, na época, depois de alguns esclarecimentos e discussões, expliquei como entendia a questão. Dona Josefa sabia, penso eu, fazer a conta. O que ela não sabia era pegar a folhinha e fazer as continhas de acordo e a partir da ordem de arme e efetue que caracterizam este tipo de atividade na escola. $\mathrm{O}$ que ela não sabia era colocar o seu saber em diálogo com o que a professora buscava a todo custo lhe ensinar: como se fazem contas na escola. Penso, ainda, que essa era uma possibilidade, embora hoje minha reflexão me leve a não estar certa disso. Por outro lado, para ambas as interpretações que pude fazer da questão, vale a idéia de que os conteúdos escolares precisam ser compreendidos em seu significado social para que sua aprendizagem seja potencializada.

Outra história interessante, que mostra a dificuldade de comunicação entre as populações que procuram os cursos de EJA e a linguagem especificamente escolar, foi ouvida por uma amiga em um ponto de ônibus no Rio de Janeiro. Duas senhoras conversavam sobre as dificuldades que enfrentavam com a escola. No diálogo entre as duas, minha amiga ouviu: "Eu agora já entendi. Problema é aquilo que a gente tenta resolver na escola e pobrema são as coisas que a gente tem que resolver na vida da gente. Entendeu?" 
Talvez fosse desnecessário comentar o que a fala evidencia. A tentativa da escola de trabalhar a matemática dos anos iniciais com "situaçõesproblema" que trariam um sentido de realidade ao ato de fazer contas fracassa diante da evidente inadequação entre o modo como os "problemas" são apresentados e os "pobremas" reais que habitam o cotidiano dos educandos. Cabe, ainda, ressaltar que não me refiro apenas aos termos da linguagem em seu sentido mais estrito, mas a toda uma forma de se conceber os processos de vida e de comunicação que vão muito além das palavras utilizadas. A lógica que preside a organização da escola e as propostas de trabalho que ela busca pôr em prática trazem embutidos valores, idéias e concepções de mundo bastante diferentes do público que a freqüenta, o que dificulta imensamente ao educando realizar o enredamento daquilo que se diz e se propõe na escola com os saberes que traz de sua vivência. Com isso, os processos de aprendizagem não se efetivam de acordo com as expectativas, nem de uns, nem de outros.

\section{Fragmentando o mundo: os jovens e adultos do ensino regular e os currículos}

No mesmo sentido, as escolas regulares enfrentam dificuldades de comunicação entre os jovens e seus professores decorrentes do mesmo tipo de inadequação. É comum observarmos situações escolares nas quais os professores buscam explicar alguns conteúdos aos alunos, de acordo e a partir de suas próprias perspectivas e entendimentos, e estes não compreenderem o que ocorre, ou não terem nenhum de seus interesses despertados pela aula. Mais uma vez, o que percebemos é que os critérios e modos de seleção e organização curricular não buscam dialogar nem com os saberes nem com os desejos e expectativas dos jovens a que se destinam, permanecendo enclausurados nas certezas de uma "ciência" que, em nome das suas supostas objetividade e neutralidade, abdica de se comunicar com o mundo das pessoas. A linguagem e a lógica que a preside na escola também não dialogam com as dos alunos jovens, sejam eles oriundos de classes desfavorecidas ou não. Além disso, na imensa maioria das propostas curriculares, a própria organização e seleção de conteúdos não segue em nenhum momento a complexidade do estar no mundo, da vida 
cotidiana e das aprendizagens que nela ocorrem. Mas, apesar de todas essas dificuldades e entraves, a vida real nas escolas, sejam elas de crianças, de jovens ou de adultos, não ocorre apenas em função das propostas e prescrições curriculares que são formuladas, mas incorporam no seu cotidiano as experiências, saberes e possibilidade dos sujeitos envolvidos na prática cotidiana do ensinar/aprender. Ou seja, apesar da estruturação desfavorável do trabalho, muitos saberes e aprendizagens circulam por nossas escolas e pelos nossos alunos.

\section{Superando o formalismo e inventando novas formas de organização curricular}

Infelizmente, boa parte das propostas curriculares tem sido incapaz de incorporar essas experiências, pretendendo pairar acima da atividade prática diária dos sujeitos que constituem a escola. Existe, ainda, uma predominância dessa abordagem formalista dos currículos, que se situa numa tendência geral do pensamento dominante nas sociedades ditas ocidentais: a da superioridade do saber teórico sobre o prático, dos saberes dos experts sobre os saberes daqueles que vivenciam as situações, do trabalho intelectual sobre o trabalho manual. Esta tendência, desenvolvida a partir do renascimento e do pensamento cartesiano e tornada inequivocamente hegemônica com o advento do positivismo a partir do século XIX, tem servido aos propósitos de legitimação dos mecanismos de dominação social e política das populações subalternizadas pelas elites sociais. Isto pode nos ajudar a compreender o porquê de, mesmo diante de estudos, debates e críticas como a que desenvolvemos acima, os currículos escolares destinados à EJA ainda se organizarem do mesmo modo que o destinado às crianças, ou do porquê as experiências, interesses e modos de estar no mundo específicos dos jovens são ignorados pelas propostas curriculares do ensino médio e das universidades. A cientifização das explicações do mundo e dos processos sociais tem permitido a legitimação de interpretações dadas como eternas, porque cientificamente comprovadas, dos diversos processos sociais dinâmicos e singulares vividos nos diversos espaços/ tempos sociais. 
Através dos mecanismos de organização, classificação e generalização oriundos das chamadas ciências duras, as elites têm construído e difundido modelos de compreensão do mundo e dos processos sociais que trazem consigo a idéia de que a sociedade, bem como suas instituições, precisam ser tratadas como um objeto de pesquisa, distante do observador/ sujeito social, sujeito a regras e leis que não deixam margem à intervenção desses mesmos sujeitos, dado o caráter perene e natural daquilo que nelas acontece. Assim, o currículo é definido formalmente, proposto por experts a partir do estudo de modelos idealizados da atividade pedagógica e dos processos de aprendizagem dos que a ela serão submetidos, bem como da escolha daquele que melhor se adequar aos objetivos, também idealizados, da escolarização e avaliado segundo sua adequação ao modelo proposto. Contrariamente a esse tipo de entendimento que congela e negligencia toda a riqueza dos processos reais da vida social e, portanto, escolar, seria necessário desenvolver novos modos de compreensão, revertendo-se a tendência dominante de entendimento do currículo.

Superar esse entendimento formalista e cientificista do currículo, buscando entendê-lo como oriundo de múltiplos e singulares processos locais de tessitura curricular, requer o estudo e o interesse no fazer aparecer as alternativas curriculares efetivas construídas cotidianamente pelos sujeitos das práticas pedagógicas, e já em curso em muitas escolas/classes do Brasil inteiro. Uma prática curricular consistente somente pode ser encontrada no saber dos sujeitos praticantes do currículo, sendo, portanto, sempre tecida em todos os momentos e escolas/classes. Nessa perspectiva, emerge uma nova compreensão de currículo. Não se fala de um produto que pode ser construído seguindo modelos pré-estabelecidos, mas de um processo por meio do qual os praticantes do currículo ressignificam suas experiências a partir das redes de poderes, saberes e fazeres das quais participam. Esse processo, que se dá de múltiplas formas, tem gerado variadas possibilidades de organização curricular, algumas mais conhecidas e aceitas, outras menos divulgadas, mas igualmente válidas enquanto manifestações de alternativas práticas tecidas no cotidiano das escolas/classes. É, certamente, a elas que devemos nos dirigir para pensar nas possibilidades de tecer propostas curriculares voltadas para a superação dos problemas que denunciamos e buscamos explicar acima.

É preciso, portanto, repensar, nos diversos espaços de discussão curricular criados nas escolas e em outros espaços de debate, algumas das máximas aceitas como base das propostas curriculares, tais como as formas e critérios de agrupamento de alunos, de organização dos conteúdos, 
dos métodos de ensino e dos procedimentos de avaliação que lhes são subjacentes.

Em primeiro lugar, por mais que se busque associar os alunos em níveis/séries ou turmas por características semelhantes, tais conjuntos sempre serão formados por uma multiplicidade de sujeitos, em si mesmos múltiplos. Nenhum professor lida em uma mesma sala de aula com um grupo homogêneo de sujeitos, sejam quais forem os critérios de ordenação utilizados. Cada sujeito traz para dentro da sala de aula redes de saberes, tecidas em seus múltiplos espaços/tempos de experiência, e participa das redes tecidas na sala de aula.

Isso significa que, a despeito de todo o aparato legal e formal do currículo, o trabalho pedagógico sempre se realizará tendo por fundamento essa multiplicidade. Significa, também, que, apesar da seriação e dos procedimentos classificatórios de avaliação, uma sala de aula sempre será constituída de sujeitos que sabem uma série de coisas e deixam de saber outras, num processo incontrolável por quaisquer instrumentos formais, sejam eles de organização de conteúdos ou de avaliação de aprendizagens. Quanto maiores as possibilidades abertas pelo currículo formal para dar conta dessa multiplicidade, mais ele estará inserido no cotidiano da experiência escolar. Quanto mais fechado e definidor se pretender o currículo formal, menos associações terão com a dinâmica cotidiana das salas de aula. Ou seja, ao invés de prescrever o que deve ser a escola, uma proposta curricular precisa dialogar com aquilo que ela é.

A segunda questão relacionada à organização curricular diz respeito à seleção e organização dos saberes que farão parte do currículo escolar. Ao longo dos anos, a organização mais tradicional dos saberes escolares se fez em matérias ou disciplinas. Mas como e a partir de que critérios foram agrupados os saberes em disciplinas ou matérias? Algumas matérias, como a física, a história, a sociologia, entre outras, se criaram nos moldes de disciplinas científicas, construindo o seu corpo de conhecimentos a partir da forma de organização da ciência-mãe. Outras foram definidas pela junção de disciplinas científicas que se julgaram associáveis. Por exemplo, as ciências, os estudos sociais. Outras, ainda, se constituíram em razão da importância que determinados conjuntos de conteúdos tiveram em certos momentos históricos - a educação física, o programa de saúde, a música. Nestes dois últimos casos, pode-se considerar que se trata muito mais de campos de saber do que de disciplinas no sentido estrito. Pode-se ainda dizer que as matérias escolares são grandes classes segundo as quais se agrupam alguns dos saberes que penetram na escola. Os critérios de cria- 
ção dessas classes e de inserção de um determinado saber nessa ou naquela classe são sempre históricos e se constroem nas redes de relações que se estabelecem entre esses saberes escolares e os demais saberes sociais (MACEDO et al., 2002).

As propostas de uma interdisciplinaridade postas hoje sobre a mesa apontam, no contexto de uma perspectiva arbórea, para integrações horizontais e verticais entre as várias ciências; numa perspectiva rizomática, podemos apontar para uma transversalidade entre as várias áreas do saber, integrando-as, se não em sua totalidade, pelo menos de forma muito mais abrangente, possibilitando conexões inimagináveis no paradigma anterior (GALLO, 1999, p. 33).

Não existem, portanto, critérios que possam ser chamados de científicos para a seleção e organização dos saberes escolares. Essa constatação leva a uma série de questionamentos que precisam ser considerados em qualquer processo de organização curricular e, particularmente, no desenvolvimento de uma proposta curricular para a EJA.

Mesmo considerando as disciplinas escolares derivadas das disciplinas científicas, caso em que parece haver um critério científico de seleção, vê-se que, na realidade, tal critério é também um juízo de valor, na medida em que algumas ciências são aceitas como disciplinas escolares e outras não. Sabe-se, por exemplo, que em determinados momentos da história da educação brasileira disciplinas científicas como a sociologia ficaram de fora do currículo escolar e outras, como a antropologia e a geologia, ainda hoje não estão inseridas nos currículos oficiais. No ensino fundamental, a ciência natural privilegiada tem sido a biologia, sem que se saibam os motivos nem o sentido dessa escolha e, no entanto, quando se está disposto a discutir os currículos desse nível de ensino, raramente se pensa em questionar essa situação e os possíveis critérios que possam ter levado a essa escolha. Portanto, questionar o caráter supostamente científico da organização curricular tradicional envolve não apenas integrar conteúdos de áreas diversas, mas repensar a própria seleção de conteúdos e a disciplinarização à qual são submetidos os saberes que integram essas propostas.

A situação fica ainda mais complicada se imaginamos que as disciplinas escolares não são as disciplinas científicas. Ao selecionar os conceitos que serão tratados, por exemplo, na matéria física, ao organizá-los de uma ou outra maneira, ao apresentá-los de uma forma específica, se está criando uma organização diferente daquela existente na ciência. Cria-se um campo específico, o da física escolar, cujo princípio estruturador é muito mais pedagógico do que científico. Em resumo: essas questões apenas indicam que a seleção de 
conteúdos e a sua inserção em campos disciplinares específicos da escola nada têm de técnico, fazendo-se como um processo histórico e conflituoso.

Os limites e as deficiências dos saberes locais não justificam a recusa in limine destes, porque isso significa o desarme argumentativo e social de quantos são competentes neles. Se o objetivo é ampliar o espaço de comunicação e distribuir mais equitativamente as competências argumentativas, os limites e as deficiências de cada um dos saberes locais superam-se, transformando esses saberes por dentro, interpenetrando-os com os sentidos produzidos em outros saberes locais (SANTOS, 1989, p. 159).

Ao longo da história, formas alternativas de organização curricular foram desenvolvidas, desde a busca da integração entre as disciplinas numa perspectiva interdisciplinar, passando pelos currículos organizados em projetos ou centros de interesse, até o uso da idéia freiriana de se partir daquilo que o aluno já conhece para chegar aos saberes formais. Mais recentemente, outras alternativas têm-se pautado no questionamento mais radical da idéia disciplinar. Uma dessas alternativas apresenta o princípio da transversalidade no currículo, argumentando que o conhecimento não se cria nos campos de saber previamente delimitados, mas segundo a lógica das redes, ou seja, saberes diversos, sob a forma de informações explícitas ou de observações e vivências práticas se articulam com outros, dos quais já se dispunha anteriormente, modificando os sujeitos e as formas de compreensão do mundo que cada um possui. De acordo com esse modo de pensar os processos de tessitura dos conhecimentos, um mesmo saber faz parte de diferentes campos significativos, tanto disciplinares quanto não disciplinares, na medida em que os enredamentos entre os diversos saberes se atravessam mutuamente, sem uma forma ou processo organizável de fora ou de acordo com os critérios "científicos". Dessa forma, a navegação por diversos campos de sentido passa a ser central no processo de conhecimento do mundo. Restitui-se, assim, a legitimidade de um conjunto de redes de saberes, poderes e fazeres presentes no cotidiano, mas normalmente expulsos do ambiente escolar, que podem e devem ser recuperados no desenvolvimento de propostas curriculares, particularmente para a EJA. 


\section{Entendendo os conteúdos como meio e para uma vida mais plena}

Considerando a importância específica que tem na EJA o desenvolvimento do trabalho pedagógico a partir das histórias de vida, dos interesses e dos saberes que os alunos trazem para as salas de aula, a reflexão sobre a questão dos conteúdos a serem trabalhados assume uma dimensão que lhe é específica. O debate torna-se, então, incontornável. Vamos a ele.

Em primeiro lugar, a lógica que deve presidir a seleção e apresentação dos conteúdos aos alunos é a da Educação de Jovens e Adultos e não a do Ensino Regular. Entende-se por isso uma abordagem dos conteúdos relacionando-os, tanto quanto possível, a situações da vida cotidiana das populações trabalhadoras pouco ou nada escolarizadas, ausentes das escolas regulares ou não - por longo período. Populações às quais o direito à escolarização foi historicamente negado. Em algumas regiões do país, muitos desses alunos adultos e trabalhadores foram "escolarizados" através de situações não legalizadas ou reconhecidas, mas de nítido perfil escolar, configurando-se como um público específico.

Podemos dizer que, com relação à seleção dos conteúdos, cabe ressaltar a necessidade de uma lógica que os compreenda não como uma finalidade em si, mas como meio para uma interação mais plena e satisfatória do aluno com o mundo físico e social à sua volta, oportunizando a essas populações a valorização dos saberes tecidos nas suas práticas sociais em articulação com saberes formais que possam ser incorporados a esses fazeres/saberes cotidianos, potencializando-os técnica e politicamente. $\mathrm{Na}$ seleção dos conteúdos a constar dos programas de escolarização, a prioridade seria, então, a da abordagem de conhecimentos relacionados à vida social e à compreensão dos elementos que intervêm na vida cotidiana. As formas mais tradicionais de seleção e abordagem dos conteúdos encontradas no Ensino Regular devem dar lugar a formas alternativas que possam favorecer a escolarização de trabalhadores anteriormente excluídos deste processo. Nesse sentido, a definição prévia e coletiva de princípios norteadores do trabalho de seleção e organização dos conteúdos torna-se um instrumento valioso para o trabalho na EJA, na medida em que incorporam essas prioridades.

Algumas inovações na criação dos instrumentos de avaliação para a EJA, propostas nas Matrizes Curriculares de Referência do SAEB, vêm ao encontro dessas preocupações. De acordo com este documento, os conteúdos das avaliações devem aparecer não apenas através do nome pelo 
qual são tradicionalmente chamados pelos profissionais da área, mas de modo mais esmiuçado e associado a formas concretas através das quais serão abordados nos exames. Essa parece ser uma boa estratégia para evitar que, ao se deparar com a nomenclatura oficial, o aluno busque o termo e sua definição como conteúdo de estudo - o que é um equívoco podendo compreender melhor o que vai ser exigido no exame e dedicar-se ao estudo do que efetivamente deve ser sabido por ele neste campo.

Que conteúdos são necessários para jovens e adultos que buscam uma escolarização tardia? A resposta poderia ser a de que os conteúdos necessários são aqueles que podem ser utilizados na vida cotidiana como meio para a autonomia do sujeito. Baseado na Declaração de Jomtien (In: OLIVEIRA e PAIVA, 2004), entende-se que "a escola deverá incorporar efetivamente os conhecimentos - conteúdos e competências - necessários para que o indivíduo possa desenvolver-se física, afetiva, intelectual e moralmente, a fim de desempenhar-se com autonomia no âmbito político, econômico e social no seu contexto de vida." (p.9).

Os objetivos do trabalho pedagógico deixariam de ser apenas os de levar ao aluno alguns conhecimentos escolares clássicos formais e passariam a incorporar as possibilidades dos conteúdos de contribuírem para as ações concretas que os alunos devem ser capazes de desenvolver na sua vida cotidiana, tanto para melhorar sua própria qualidade de vida como para associar esta com a vida do conjunto da sociedade.

Isso significa que alguns conteúdos formais clássicos devem ser abandonados em prol de outros que sejam operacionais, ou seja, que possam contribuir para uma capacitação da ação social dos alunos. Assim sendo, a principal preocupação do trabalho pedagógico, bem como dos processos de avaliação, não deve ser o "saber enciclopédico", mas saberes que contribuam para o desenvolvimento da consciência crítica e para esta capacitação, sem que isso signifique uma opção por um qualquer tipo de minimização, como foi e ainda é preconizado por alguns. Não se trata de reduzir conteúdos para "facilitar", mas de adequar conteúdos a objetivos mais consistentes do que o da mera repetição de supostas verdades universais desvinculadas do mundo da vida. 


\section{Considerações finais}

Pensar em currículo na EJA exigiu passear um pouco na história desta no Brasil e dos problemas que as concepções que predominaram nos diversos momentos criaram e consolidaram algumas das idéias que vêm prejudicando as possibilidades de mudanças no campo. Da educação compensatória às propostas e práticas curriculares infantilizantes e formalistas, muitos são os entraves ao desenvolvimento de um trabalho mais apropriado ao perfil dos alunos dessa modalidade de ensino. Por outro lado, se entendemos os processos de tessitura de conhecimentos como organizados em redes, percebemos que, apesar das propostas e do pensamento dominante na nossa sociedade, muito já existe em nossas escolas e classes que ajuda a ter uma visão otimista das possibilidades de enfrentamento dos problemas. Assim, buscando na reflexão curricular as alternativas possíveis, mais ou menos formuladas e praticadas, encontramos explicações sobre o caráter arbitrário de muitas "verdades" que sustentam as propostas tradicionais, bem como alternativas fundamentadas e coerentes a elas.

Portanto, acho que podemos ser, de fato, otimistas. Não com relação a uma qualquer solução mágica, como disse no início, mas exatamente por sabermos que estas não existem e que a impossibilidade de pensar grandiosamente - como fizeram muitos de nossos dirigentes até aqui, com os resultados que conhecemos - nos permite pensar e agir sobre a realidade cotidiana que vivenciamos, transformando-a através de pequenas ações e mudanças, tecidas coletivamente com nossos pares, buscando tornar nossos fazeres e saberes mais apropriados aos nossos objetivos e perseverando, sempre, com consciência das dificuldades, mas acreditando que há possibilidades de mudar, de fazer. Desistir da impossível solução global dos problemas através de receitas sobre como e o que fazer é, portanto, necessário para nos debruçarmos sobre aquilo que é possível fazer, sem que isso nos traga frustrações, mas alegrias nas pequenas e cotidianas realizações. 


\section{REFERÊNCIAS}

GALLO, S. Transversalidade e educação: pensando uma educação não-disciplinar. In: ALVES, N.; GARCIA, R. L. O sentido da escola. Rio de Janeiro: DP\&A, 1999.

MACEDO, E.; ALVES, N.; MANHÃES, L. C.; OLIVEIRA, I. B. Criar currículo no cotidiano. São Paulo: Cortez, 2002.

OLIVEIRA, I. B. de. Currículos praticados: entre a regulação e a emancipação. Rio de Janeiro: DP\&A, 2003.

OLIVEIRA, I. B. de; PAIVA, J. Educação de jovens e adultos. Rio de Janeiro: DP\&A, 2004.

SANTOS, B. de S. Um discurso sobre as ciências. Porto: Afrontamento, 1989.

Texto recebido em 07 de nov. 2006 Texto aprovado em 01 de fev. 2007 